\title{
NOTAS
}

\section{UNA FUENTE POÉTICA DE GONZALO CORREAS}

El propósito de esta nota es llamar la atención sobre un hecho curioso: al reunir los materiales para su Vocabulario de refranes $y$ frases proverbiales y también para su Arte de la lengua española castellana, Gonzalo Correas parece haber tenido a la vista, en algún momento, el cartapacio poético manuscrito que ahora se encuentra en la B.N.M., con el número 3915 (antiguo M-4). Su fecha y proveniencia se explican claramente en la hoja inicial: "Por el Conde de Ribadauia con el conde de Monterrey. De la mano y pluma de Jacinto Lopez musico de su Magd. En la villa de Madrid a veynte dias del mes de Enero del año passado de mil y seyscientos y veinte". 1620: el comienzo de la década en que Correas daría fin a su gran recopilación de refranes, giros y canciones populares (ca. 1627) y a su Gramática (1625); ésta, como es sabido, contiene un tratado de versificación, en el que Correas concede notable atención a las formas poéticas de tipo popular y las ilustra con abundantes ejemplos.

Dado ese interés científico por las manifestaciones "folklóricas", y dadas las noticias que nos han llegado sobre la manera como recogía Correas los proverbios y dichos, sería de esperar que -fuera de los textos que sabemos que tomó de refraneros anteriores, como los de Pero Vallés y Hernán Núñez- la mayoría de sus materiales procediera de la tradición oral. $\mathrm{Y}$ así es, sin duda. A la vez, coincidencias como las que apuntaré en seguida con el ms. 3915 parecen probar que Correas utilizó también fuentes literarias ${ }^{1}$. Aunque, para este caso al menos, la palabra "fuente" no sea quizá la más adecuada.

De las coincidencias que he encontrado entre textos del manuscrito poético y textos del Vocabulario y del $A r t e^{2}$, no todas dicen algo: Correas no tuvo que conocer el cancionero de Jacinto López para citar cantarcillos tan conocidos como "Estos mis cabellos, madre...", o "Si

1 Se sirvió, por ejemplo, del Guzmán de Alfarache, según ha observado recientemente Francisco Rico. [Cf. el artículo de Monieue Joly, infra, p. 96, nota 7].

2 Referencias bibliográficas: Vocabulario $=$ Gonzalo Correas, Vocabulario de refranes y frases proverbiales, texte établi, annoté et présenté par Louis Combet, Bordeaux, 1967; Arte = Gonzalo Correas, Arte de la lengua española castellana, ed. y pról. de Emilio Alarcos García, Madrid, 1954 (RFE, anejo 56); Séguedilles $=$ R. Foulcrí-Delbosc (ed.), "Séguedilles anciennes". RHi, 8 (1901), 309-331. 
queréis que os enrame la puerta...", o "Que no me los ame nadie...", o "Un poco te quiero, Inés, / yo te lo diré después". En cambio, nos interesan los textos que, por lo menos hasta ahora, no se han encontrado más que en el ms. 3915 y en Correas: son nada menos que nueve; y nos interesan otros cuatro casos (los núms. 2, 4, 6 y 7) en que, también según lo que sabemos hasta hoy, el texto sólo aparece en una fuente más. Trece coincidencias así no son desdeñables:

Ms. 3915

1

A la una bine aquí, señora, ia son las dos; no fuisteis para dezir:

"Arrimáos a essa carreta".

(f. $319=$ Séguedilles, 317).

2

Ándome en la billa

fiestas principales

con mi ballestilla

de matar pardales.

(f. 163v; glosado: "Unos de bai-

lar..." - Con la misma glosa en un cancionero ms. de Florencia).

3

Bálgate la mona, Antona, bálgate la mona.

(f. 67; glosado: "De tal suerte amor me inflama...").

4

A la mal casada le dé Dios plazer, que la vien casada no lo á menester.

\section{Gonzalo Correas}

1

A la una vine aquí, señora, ia son [las] dos; no fuistes para dezir:

"Arrimáos a esa carreta". (Arte, p. 426).

2

Ándome en la villa

fiestas prinzipales

kon mi ballestilla

de matar pardales.

(Vocabulario, p. $7 b$ ).

3

Válate la mona, Antona, válate la mona. [En prosa].

(Vocabulario, p. 515a).

\section{4}

A la mal kasada déla Dios plazer, ke la bien kasada no lo á menester. [En prosa].

(Vocabulario, p. $7 b$ )

3 "Estos mis cabellos, madre, / dos a dos me los lleva el aire" está en el ms. 3915, f. 69v, en el Vocabulario, p. 153a, y en el Arte, p. 465; "Si queréis que os enrame la puerta", en el f. 319 del ms. (三 Séguedilles, 319) y en la p. 455 del Arte; "No me los ame naide...", en el $\mathrm{ms}$, f. $319 \mathrm{v}$ (= Séguedilles, 327) y en el Arte, p. 455; "Un poco te quiero, Inés..." (con la glosa "El primer día que baias..."), en el ms., f. 190v, y (sin glosa) en el Vocabulario, p. 177b. Mencionemos de pasada que en el $\mathrm{ms}$. 3915, como en otras colecciones poéticas de la época, se encuentran coplas basadas en un refrán, de los recogidos, entre otros, por Correas: "Quanto me mandareis / todo lo aré: / cassa de dos puertas / no la guardaré" (f. 318v = Séguedilles, 11) (cf. Vocabulario, p. 503a: "Todo lo haré..."); "Si el galán es avisado / i la dama se pica de loca, / anden las manos / y calle la boca" (f. 318v) (cf. Vocabulario, p. 279b: "Si la mozuela fuera loka..."). Del mismo tipo parece ser la correspondencia entre "Que no me llebéis, / marido, a la boda, / que no me llebéis, / que me brincaré toda" (ms., f. 65v) y "No me llevéis, marido, a la boda, ke me brinkaré toda" (Vocabulario, p. 262a). 
(f. 66; glosado: "Triste y ocupada..."; sin glosa en f. $320=$ Séguedilles, 24 [v. 4, "no le á"].-También en B.N.M., ms. 3168 , f. 43 , con glosa parcialmente distinta de la del ms. 3915, f. 66) .

$$
5
$$

Mi marido es cucharetero:

diómelo Dios y así me le quiero.

(f. 68v; glosado: "Mi marido aze cuchares...").

$$
6
$$

Tras las niñas me como los dedos que ni piden ni hazen entredos.

(f. 82; glosado: "Como veo ser tramposas..."-Misma glosa ya en Flor de varios romances, Huesca, 1589 , f. 57).

\section{7}

Pastorcilla mía, pues de mi te bas, ¿quándo bolverás?

(f. 66; glosado: "Como en tu presencia..."; también en f. 184, glosado: "Quándo será el día..."-Con esta segunda glosa, en el cancionero florentino mencionado supra, núm. 2).

\section{8}

La piedra que mucho roda no es buena para çimiento; la muger que a muchos ama tarde cobra casamiento.

(f. $318=$ Séguedilles, 297) .

\section{9}

Canta la gallina, responde el capón: mal aia la casa donde no ai barón.

(f. $320=$ Séguedilles, 25) .

10

El abad i su manseba, el herrero $i$ su muger de dos huebos comen sendos: esto ¿cómo puede ser?

(f. $320=$ Séguedilles, 389) .

\section{5}

Mi marido es kucharatero, Dios me lo dio i ansí me lo kiero. [En prosa]. (Vocabulario, p. 553a).

\section{6}

Tras las niñas me chupo los dedos ke ni piden ni hazen entredos. [En prosa].

(Vocabulario, p. 509b).

\section{7}

Pastorzilla mía, pues de mí te vas, dime kuándo bolverás. [En prosa]. (Vocabulario, p. $461 b$ ).

\section{8}

La piedra ke mucho rroda no es buena para zimiento; ia moza ke a muchos ama tarde halla kasamiento.

(Vocabulario, p. 196a; cf. ibid., p. $469 b$ :

"Piedra rrodadera...").

\section{9}

Kanta el gallo, rresponde el kapón: iguai de la kasa donde no ai varón! [En prosa].

(Vocabulario, p. 372a).

10

El abad i su manzeba, el barvero i su muxer de tres güevos komen sendos, esto ¿kómo puede ser? [En prosa].

(Vocabulario, p. 85a). 
Bistete de berde, qu'es linda color, como el papagaíto del rrei mi señor.

(f. $319=$ Séguedilles, 14).

12

Aunque soi morena, blanca io nascí: guardando el ganado la color perdí.

(f. $320=$ Séguedilles, 26) .

13

Aunque soi morenita un poco, no me doi nada:

con el agua del almendruco

me lavo la cara.

(f. $318=$ Séguedilles, 298) .

Vestime de verde, ke es buena kolor, komo el papagaio del Rrei mi señor. (Vocabulario, p. 519a) .

Aunque soi morena, io blanca nazi, a guardar ganado mi color perdi. (Arte, p. 453).

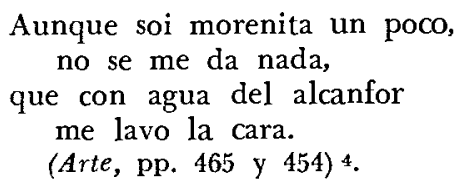

Viendo así en conjunto las coincidencias, es difícil pensar que se trata de una mera casualidad. Al mismo tiempo se observa que sólo dos textos (núms. 1 y 2) son idénticos en el ms. 3915 y en Correas; todos los demás presentan variantes más o menos leves, de inversión o sustitución de dos o más palabras. Es poco probable que Correas hiciera retoques caprichosos a los textos que recogía. Más bien da la impresión de que, al leer los cantarcillos del cartapacio, se iba acordando de las versiones ligeramente discrepantes que él conocia, y que prefirió registrar éstas en vez de copiar las del cancionero. $\mathrm{O}$ sea que, según parece, la compilación de Jacinto López sirvió, más que de fuente, de estímulo para la memoria del recolector.

Vale la pena observar que con su fuente principal, los Refranes o proverbios en romance (Salamanca, 1555) de Hernán Núñez, Correas procedió a este respecto de manera algo distinta: por lo general anotó tanto las versiones del Comendador como las que él recordaba o había recogido en otras fuentes orales y escritas: junto a "Si no fuerdes en esta barketa, irés en la otra ke se kalafeta" (Vocabulario, p. 280b), que procede textualmente de Núñez, f. 120v, recogió estas dos: "Si no fuere en esta barketa, irá en esotra ke se kalafeta" y "Si no fuere en esta barketa, iré en esotra ke se fleta". Probablemente el refranero del Comendador le parecía una fuente más digna de crédito, en cuanto a su fidelidad a la tradición oral, que un cancionero poético. ( $\mathrm{Y}$ no le faltaba razón).

Además de esas versiones ligeramente discrepantes, Correas solía agrupar dos o más refranes o cantares de distinta procedencia empa-

4 En la p. 454, Alarcos García suprime las palabras "un poco", que figuran en el ms., aunque medio tachadas. 
rentados entre sí por su sentido y su esquema sintáctico, pero con rima diferente (como si fueran estrofas de un cantar paralelístico): de Núñez, f. 86, copia "No entres en g[ü]erto axeno, ke te dirá mal su dueño", y de otra fuente, quizás oral, el refrán que figura inmediatamente antes (Vocabulario, p. 246a): "No entres en lo vedado, ke te prenderá su amo". Lo mismo ha ocurrido con tres textos del ms. 3915: tras "Kanta el gallo..." (núm. 9) figura "Kanta el gallo, rresponde la gallina: ¡Amarga la kasa do no ai harina!" (tomado de Núñez, f. 22) ; a continuación de "Tras las niñas me chupo los dedos..." (núm. 6) está "Tras las mozas me komo las manos, ke ni piden ni hazen engaños (u desgarros)", el cual podría proceder de la tradición oral, lo mismo que el precioso "Vestime de verde / por hermosura, / komo haze la pera / kuando madura", que acompaña a "Vestime de verde..." (núm. 11).

Algo podremos ir aprendiendo sobre el modo como trabajó ese hombre extraordinario que fue Gonzalo Correas. Aunque será inevitable que nos quedemos con ciertas dudas. ¿Cómo explicar, por ejemplo, que si tuvo a la vista el cancionero de Jacinto López, no tomara de él todas las cancioncitas de estilo popular y que dejara fuera cosas del tipo de "Aunque soi morena, / no soi de oibidar, / que la tierra negra / pan blanco suele dar" (f. 320v = Séguedilles, 340) ? 5 Si tanto en el Arte (p. 449) como en el Vocabulario (pp. $528 b$ y 167a) recogió, con variantes, la seguidilla "Mal aia la falda / del mi sombrero, / que me quita la vista / de quien bien quiero", ¿por qué no incorporó estas dos del cancionero (f. $318=$ Séguedilles, 1 y 2) ?:

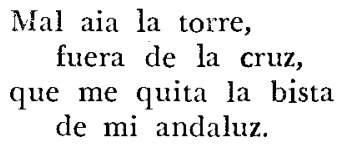

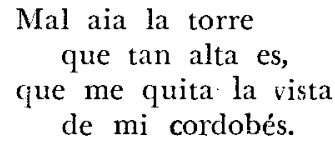

Y puesto que le gustó aquello de "--Ved, marido, si keréis algo, ke me kiero levantar. -Muxer, no seáis tan pesada, levantáos, ke no kiero nada" (Vocabulario, p. 519b; cf. "Marido, si keréis algo...", p. 526a), ¿cómo no le interesó la versión del ms. (f. $319=$ Séguedilles, 315 ) ?:

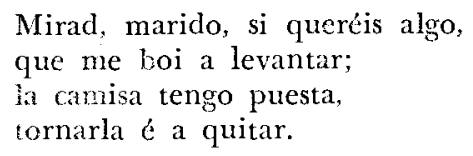

En realidad, nos topamos aquí con un problema más amplio y general: el de por qué Correas acogió textos poéticos en su Vocabulario, con qué criterio los seleccionó y aun por qué escribió la mayoría de esos textos como si fueran prosa. En otra ocasión he hablado de los cantares incorporados en los refraneros antiguos y de cómo Juan de Mal Lara se planteó abiertamente la cuestión de si podían o no equi-

5 Cf. en el Vocabulario, pp. 197b-198a, los muchos refranes del tipo "La tierra negra buen pan lleva..." ( $y$ p. 190b, "La buena tierra negra..."). 
pararse las canciones con los proverbios: "Yo no tengo por qué rehusar los refranes que puso [Hernán Núñez], aunque a!gunos son cantarcillos"; pero también: "no pierde el refrán por ser cantar, porque se puede hacer el uno del otro" 6 . Correas supo igualmente, porque había podido verlo en casos concretos?, que "de cantares han quedado muchos refranes" (Arte, p. 399). Quizá esto le cliera la idea de que cualquier canción muy divulgada era un refrán en potencia y como tal podía figurar dignamente en una colección de proverbios y frases proverbiales. Assí se explicaría el enorme número de cantarcillos incorporados al Vocabulario y el hecho de que, continuando la costumbre de sus predecesores, los pusiera casi todos en prosa. Sin embargo, también es evidente, y hemos podido comprobarlo aquí, que no emprendió la recolección de cantares en forma sistemática ni con la ambición de exhaustividad con que realizó el acopio de refranes y dichos: como si, en el fondo, no estuviera tan seguro de la conveniencia de mezclar las canciones con los refranes. Si fuera lícito forjar utopías retrospectivas, yo diría que a lo mejor, de haber tenido tiempo, Correas habria acabado por separar las dos cosas y habría elaborado una obra aparte con los materiales líricos: una gran recopilación de cantares y rimas de la tradición oral...

El Colegio de México.

Margit Frenk Alatorre

\title{
ASPECTOS DEL REFRAN EN MATEO ALEMAN Y CERVANTES
}

\author{
Les beaux proverbes, bien appliquez, \\ ornent le langage de ceux qui d'ail- \\ lcurs sont bien cinparlez.
}

Henti Estienne

Siempre que se considera el problema del empleo literario del refrán surge la cuestión de la relación entre lo popular y lo culto. A ésta se alude implícitamente en las comparaciones en que se opone la naturalidad que caracterizaría el empleo de refrán en Cervantes y lo artificioso del mismo en otros autores. A principios de siglo Sainéan declaraba, por ejemplo, que "les proverbes allégués par Sancho Pança coulent comme une eau calme qui se confond avec celle de la sagesse populaire elle-même, alors que les dictons de Rabelais sont puisés à des sources plus hétérogènes et présentent les aspects les plus variés" Aunque se niega a adoptar las conclusiones del análisis de Sainéan, Eleanor O'Kane no pone en tela de juicio el contraste en que este

6 "Refranes cantados y cantares proverbializados", NRFH, 15 (1961), 155-168 (cn especial, pp. 160-163).

₹ Cf. ibid., p. 163 y nota 23.

1. L. Sarnéan, La langue de Rabelais, Paris, 1905, p. 477. 